Original article

https://www.journal-imab-bg.org

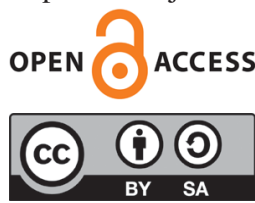

\title{
IMPAKT OF THE VERTICAL DIMENSION OF OCCLUSION AND ARRANGEMENT OF TEETH ON SPEECH ARTICULATION (QUESTIONNAIRE STUDY)
}

\author{
Majed Hussein \\ Department of Prosthetic Dental Medicine, Faculty of Dental Medicine, Medical \\ University, Plovdiv, Bulgaria.
}

\section{ABSTRACT}

Phonetic tests are one of the most important methods for the proper positioning of the teeth and identifying the vertical dimension of occlusion in denture fabrication.

Purpose: Assessment of the level of awareness of dental practitioners and dental technicians regarding the impact of the vertical dimension of occlusion and the teeth arrangement on speech articulation.

Material/Methods: 369 dental practitioners from 70 settlements (67 of which - towns and 3 - villages), and 84 dental technicians from 19 settlements (towns only) in Bulgaria were part of the research. The questionnaire study took 5 months (starting 2018).

Results: The research results prove that speech function is influenced by both the vertical dimension of occlusion (opinion of 93.80 of the dental practitioners and $85.80 \%$ of the dental technicians) and the arrangement of the artificial teeth (opinion of 94.80 of the dental practitioners and $91.70 \%$ of the dental technicians).

Conclusion: A high proportion of the inquired participants (over $90 \%$ ) admit the negative impact on the speech exerted by incorrect vertical dimension of occlusion and arrangement of teeth, and these are seen as a major factor for compromising the speech function.

Keywords: vertical dimension of occlusion, arrangement of teeth, speech

\section{INTRODUCTION}

Speech function is a major privilege of human beings, fundamental to social communication, and therefore it strongly influences their quality of life. Tooth loss is often related to various chronic constraints in performing regular functions, where mostly affected are mastication and speech function. In its turn, this causes psychosocial issues, which however can be prevented by modern prosthetic dentistry with prosthetic dentures fabricated to completely comply with the individual anatomic characteristics, thus improving both impaired functions (speech and mastication) and aesthetics.

Despite the advancement of medicine and the immense information flow, in science literature there is lack of contemporary studies on the effect, that removable dentures exert on the speech function and adaptation. The factors that influence the phonetic adaptation process in patients are yet not fully explored objectively, due to which practical guidelines for improving treatment with removable complete dentures are in shortage.

In the fabrication of dental prostheses, phonetic tests are used to determine the proper positioning of teeth, as well as the vertical dimension of occlusion, serving as a means of their assessment.

The aim of this research is to identify the dental practitioners' and dental technicians' level of awareness of the impact that the vertical dimension of occlusion and the teeth arrangement have on the articulation of speech.

\section{MATERIALS AND METHODS}

Observation units in the research were 369 dental practitioners and 84 dental technicians in Bulgaria.

The data source are specifically designed questionnaires on the awareness of the inquired.

The questionnaire for the dental practitioners is comprised of 7 questions, where the first part (5 questions) explores as variables the sex, age, work experience, and specialty of participants.

The second part of the questionnaire contains 2 questions intended to explore the dental practitioners' awareness of the effect that vertical occlusion dimension and artificial teeth arrangement in denture fabrication exert on the speech function.

The questionnaire intended for the dental technicians is composed of 6 questions, containing a general part (4 questions) concerned with variables: sex, age, and work experience of participants.

The second part comprises 2 questions designed to explore the dental technicians' awareness of the influence which vertical occlusion dimension and artificial teeth arrangement in complete denture fabrication have on the speech function.

The questionnaire study took 5 months - starting at the beginning of January 2018, ending at the end of May 2018. The inquiry participants were from 70 settlements -67 towns and 3 villages. The contributing dental 
technicians were from 19 urban settlements.

A similar type of study among dental practitioners and dental technicians has been made by other researchers. $[1,2]$

The participation of dental practitioners and dental technicians is random, without prior selection, which validates the representativeness of the sample.

The following statistical methods were used:

- Descriptive analysis - frequency distribution table representation of the observed variables;

- Variation analysis - evaluation of the characteristics of central tendency and statistical dispersion;

- Correlation analysis - checking the presence of linear correlation between quantitative features;

- Multiple regression analysis;

- Testing for statistical correlation of qualitative variables applying the $\chi 2$-criterion (chi-square);

- Graphical analysis visualizing the results;

- For the statistical processing of data we have used application package for epidemiology and clinical research - SPSS v. 22.0 for Windows.

\section{RESULTS AND DISCUSSION}

The inquired dental practitioners and dental technicians are distributed by sex, age, work experience, place of employment and specialty.

Table 1. Characteristic of inquired specialists

\begin{tabular}{|c|c|c|c|}
\hline \multicolumn{2}{|c|}{ Feature } & \multirow{2}{*}{$\begin{array}{c}\begin{array}{c}\text { Dental } \\
\text { practitioners } \\
(\mathbf{n}=\mathbf{3 6 9})\end{array} \\
300 / 82,90 \%\end{array}$} & \multirow{2}{*}{$\begin{array}{c}\begin{array}{c}\text { Dental } \\
\text { technicians } \\
(\mathbf{n}=\mathbf{8 4})\end{array} \\
78 / 95,10 \%\end{array}$} \\
\hline Place of employment & City & & \\
\hline & Town or village & $62 / 17,10 \%$ & $4 / 4,90 \%$ \\
\hline \multirow[t]{2}{*}{$\operatorname{Sex}$} & Male & $175 / 48,30 \%$ & $41 / 48,80 \%$ \\
\hline & Female & $187 / 51,70 \%$ & $43 / 51,20 \%$ \\
\hline \multirow[t]{4}{*}{ Age } & $25-35$ г. & $68 / 18,50 \%$ & $14 / 16,70 \%$ \\
\hline & $35-45$ г. & $118 / 32,20 \%$ & $25 / 29,80 \%$ \\
\hline & $45-55$ г. & $113 / 30,80 \%$ & $18 / 21,40 \%$ \\
\hline & over 55 & $68 / 18,50 \%$ & $27 / 32,10 \%$ \\
\hline \multirow[t]{5}{*}{ Work experience } & up to 5 г. & $42 / 11,40 \%$ & $4 / 4,80 \%$ \\
\hline & $5-10$ & $54 / 14,70 \%$ & $7 / 8,30 \%$ \\
\hline & $10-15$ & $72 / 19,60 \%$ & $9 / 10,70 \%$ \\
\hline & $15-20$ & $88 / 23,90 \%$ & $10 / 11,90 \%$ \\
\hline & over 20 & $112 / 30,40 \%$ & $54 / 64,30 \%$ \\
\hline \multirow[t]{4}{*}{ Specialty } & No specialty & $228 / 62,10 \%$ & - \\
\hline & GDP & $78 / 21,30 \%$ & - \\
\hline & Prosthodontists & $22 / 6,00 \%$ & - \\
\hline & Other specialty & $39 / 10,60 \%$ & - \\
\hline
\end{tabular}

Male and female participants are nearly equal in number, the females slightly prevailing in both groups dental practitioners and dental technicians. In the observed groups of specialists, we find that age index demonstrates a significant difference $(\chi 2=7.82 ; \mathrm{p}<0.05)$ showing that with the dental practitioners prevailing is the age group 34-45 (32.20\%), while with the dental tech- nicians, high relative share have those above the age of $55(32.10 \%)$.

The outcome of this research shows that $93.80 \%$ of the dental practitioners and $85.80 \%$ of the dental technicians think that the vertical dimension of occlusion affects speech. (fig. 1). 
Fig. 1. The opinion of the dental practitioners and dental technicians regarding the impact of the vertical dimension of occlusion on the speech

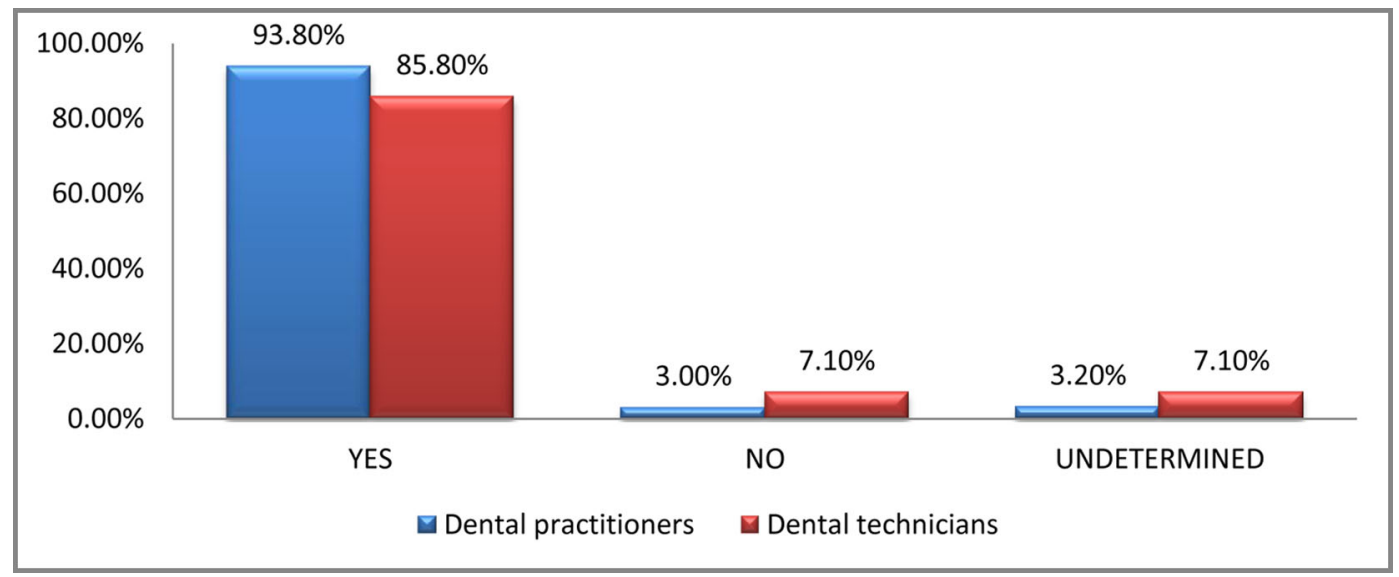

Yet in 1957, in research H. F. Kessler described that the vertical dimension of occlusion affects the size of the space within which the tongue moves, and therefore changes occur in speech [3]. Later on, in 1984, R. J. Hammond and D. E. Beder found that the sounds ,s“, ,sh“ and „t" were the most affected by the increase of the vertical dimension of occlusion [4]. Another researcher, M. E. Ribnor, summarized the benefits of the phonetic tests regarding the vertical dimension in the fabrication of dental prostheses [5]. He concluded that the insufficient height affects the articulation of the speech sounds ,"p“, „b" and ,v“.

In researching the relation between full dentures and speech, some researchers maintain that the occurring issues are due to poor fabrication. [6, 7, 8, 9].

Regarding the impact the artificial teeth arrangement on the speech function, a significant part of the dental practitioners $(94.80 \%)$ and of the dental technician (91.70\%) consider it influential (fig. 2).

Fig. 2 Opinion of the dental practitioners and dental technicians regarding the impact of the artificial teeth arrangement on the speech

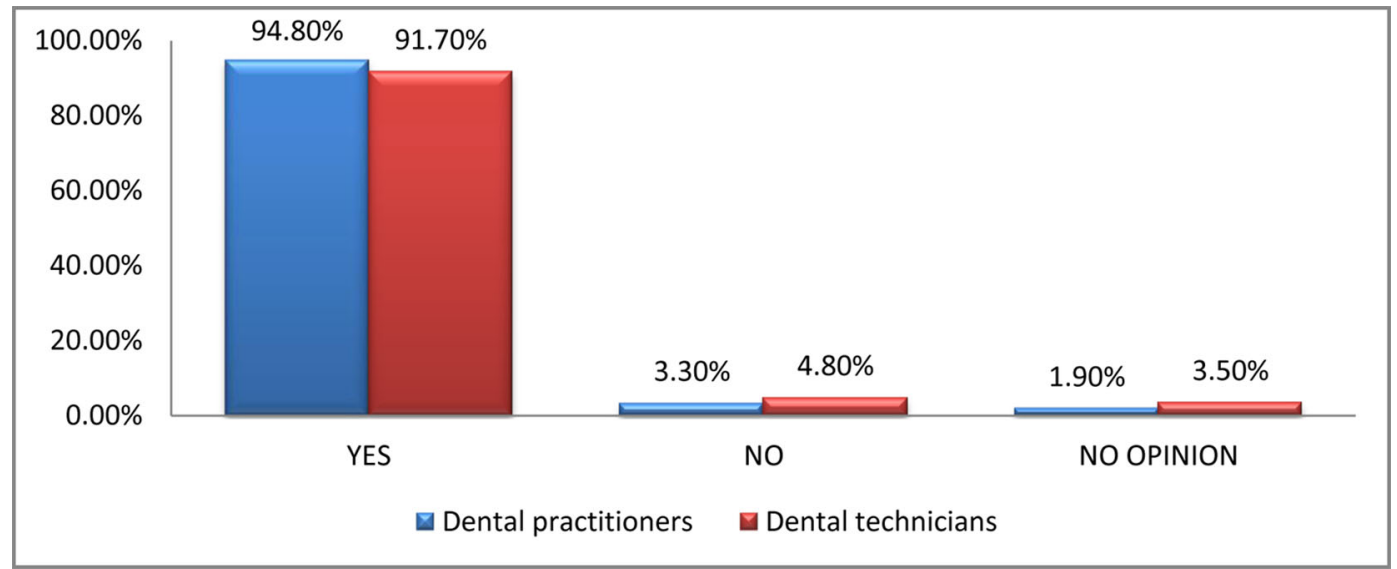

With this regard, M. E. Ribner studies the frontal teeth height using a base plate, asking the patient to articulate the speech sounds ,, ${ }^{\prime \prime}$ and ,f“. [5]. If the patient is not able to articulate these sounds, it means that the frontal teeth are either too far above or too far below the functional occlusal plane. In research E. Sebastini suggests that the replacing teeth should be placed in the same position as the original ones, i.e. phonation is influenced by the shape and arrangement of the entire dentition, preferably taking as reference their original positioning before extraction. $\mathrm{He}$, as well as other researchers, sustain that phonation depends on the symmetry in the lingual surface of the maxillary and mandibular dentures. $[10,11]$
In dentistry, the articulation of the speech sound "s" is of significant phonetic importance. In the concerned literature, it is mentioned that the "s"-sound test can be used in identifying the vertical dimension of occlusion. This method has been described as early as 1952 , and it is still valid. $[12,13]$.

Over $90 \%$ (90.4\%) of the inquired dental practitioners think that the vertical dimension of occlusion and arrangement of teeth impact the speech function, whereas a direct ratio between the two factors is found $(r=0.294$; $\mathrm{p}<0.001)$. A major portion of the dental technicians $82.20 \%$ ) support this opinion of the dental practitioners that the vertical dimension of the occlusion and the arti- 
ficial teeth arrangement influence the speech articulation of patients. A direct ratio between the factors $(r=0.218$; $\mathrm{p}<0.05)$ also is discovered.

Using the spectral analysis method, Stojevich analyses the formation mechanisms of the Croatian sounds group (dental and postalveolar), and how the removable dentures affect the accuracy of their articulation. The research proves that patients with conventional removable dentures experience by $50 \%$ less distortion of speech than those without dentures. [14]

Ozbek, on his part, studies the formation of the Turkish-language-specific sounds following a prosthetic rehabilitation. His conclusion is that certain groups of sounds are better influenced than others. [15]

Runte proves that even the slightest dislocation of the maxillary incisors causes distortion of the sound "s". It is recommended that the artificial teeth are arranged following the original position of the lost dentition [16,]. In the arrangement of the replacing teeth, it is advisable to use anatomic reference points - papilla incisiva and the first protuberant rugae palatinae, which would guarantee positioning of the teeth in accordance with the functional and aesthetic criteria $[17,18]$. It is expected that the "s"articulation test for quality assessment at the stage of wax try-in of dentures would diminish the adaptation effort and thus facilitate the phonetic adaptation of the patient [19, 20].

\section{CONCLUSION}

The questionnaire study on the level of awareness of dental practitioners and dental technicians regarding the importance of the vertical occlusion dimension and the artificial teeth arrangement influencing the recovery of the speech function in prosthodontic treatment with removable dentures has proven high percentage of wellinformed male and female professionals across the various age groups, especially among dental practitioners specializing in prosthetic dentistry.

Slightly more half of the dental practitioners $(58.70 \%)$ evaluate their awareness of the influence exerted by the removable complete dentures on the speech function as excellent, i.e. they are familiar with all the explored factors affecting that function.

Notably higher proportion of the dental technicians $(85.70 \%)$ state that they are fully aware of the influence exerted by the removable complete dentures on the speech function $(\chi 2=9.21 ; \mathrm{p}<0.001)$

Over $90 \%(90.4 \%)$ of the inquired dental practitioners deem that vertical dimension of occlusion and teeth arrangement influence the speech function, and we find a direct ratio between the two factors $(r=0.294$; $\mathrm{p}<0.001)$. A considerable percentage of the dental technicians $(82.20 \%)$ support the opinion of the dental practitioners that vertical dimension of occlusion and teeth arrangement affect the speech function. Here again, a direct ratio of the explored factors is seen $(r=0.218 ; \mathrm{p}<0.05)$.

A high percentage $(90 \%)$ of the inquired admit the negative effect from the incorrectly restored vertical dimension of occlusion and the improper arrangement of the artificial teeth, and see it as a major factor for the impediment of the speech function in patients.

For the first time in Bulgaria, there has been done a questionnaire study on the awareness of the dental practitioners and dental technicians of the complete denture related factors(vertical occlusion dimension and artificial teeth arrangement) that influence the speech function of patients. The results of our study confirm the information in the specialized literature.

\section{REFERENCES:}

1. Hristov I, Boshkova T, Yankov S, Shopova D, Zlatev S. Degree of awareness of soft relining materials by dental technicians. J of IMAB. 2017 OctDec;23(4):1726-1730. [Crossref]

2. Hristov I, Slavchev D, Shopova D, Grozev L, Chuchulska B. Application of soft relining materials by dentists - a pilot study. J of IMAB. 2017 Oct-Dec;23(4):1721-1725. [Crossref]

3. Kessler KF. Phonetics in Denture Construction. JADA. 1957 Mar;54: 347-351. [Crossref]

4. Hammond RJ, Beder OE. Increased Vertical Dimension and Speech Articulation Errors. J Prosthet Dent. 1984 Sep;52(3):401-6. [PubMed] [Crossref]

5. Ribner ME. The role of phonetics in denture construction. Dent Dig. 1965 Mar;71:106-7. [PubMed]
6. Filchev DA. [Graphic and computer design of the posterior teeth of complete dentures.] [Dissertation] Medical University Sofia. 2013. p.168. [in Bulgarian]

7. Slavchev D, Doshev At, Bozhkova T, Shopova-Karatzanova D. Flexible dentures compliant with phonetic neutral zone. [Abstract] 18th Scientific Congress of BDA, 7 - 9 June 2018. Burgas, Bulgaria.

8. Ivanov S, Drazhev Ò. [Soft resins.] Eksakt 93, Plovdiv. 2019. 203 p. [in Bulgarian]

9. Igic M, Krunic N, Aleksov L, Kostic M, Igic A, Petrovic M, et al. Determination of vertical dimension of occlusion by using the phonetic vowel "O" and "E". Vojnosanit Pregl. 2015, 72(2):123-31. [Crossref]

10. Sebastini E. Articulate speech in prosthetic dentistry. Minerva Stomatol. 1960; 9:140-151.

11. Slavchev D, Doshev V, Todorov G. [Study of the symmetry of aligned teeth for upper complete dentures via a frontal teleradiography and orthodontal methods and correlations.] [in Bulgarian] $J$ of IMAB. 2004; 10(2):78-82. [Internet]

12. Silverman MM. The speaking method in measuring vertical dimension. 1952. J Prosthet Dent. 2001 May;85(5):427-31. [PubMed]

13. Pound E. Utilizing speech to simplify a personalized denture service. 1970. J Prosthet Dent. 2006 Jan; 95(1):1-9. [PubMed]

14. Stojcevic I, Carek A, Bukovic D, Hedjever M. Influence of the Partial Denture on the Articulation of Dental and Postalveolar Sounds. Coll 
Antropol. 2004 Dec;28(2):799-807. [PubMed]

15. Ozbek M, Tulunoglu I, Ozkan S, Oktemer M. Evaluation of articulation of Turkish phonemes after removable partial denture application. Braz Dent J. 2003; 14(2):125-31. [PubMed] [Crossref]

16. Runte C, Lawerino M, Dirksen D, Bollmann F, Lamprecht-Dinnesen A, Seifert E. The Influence of Maxillary Central Incisor Position in Com- plete Dentures on /S/ Sound Production. J Prosthet Dent. 2001 May; 85(5):485-95. [PubMed] [Crossref]

17. Laurina L, Soboleva U. Construction Faults Associated With Complete Denture Wearers' Complaints. Stomatologija. 2006; 8(2): 61-4. [PubMed]

18. Inukai S, Hideshima M, Sato M, Nishiyama A, Ando T, Ohyama T, et al. Analysis of the Relationship between the Incisal Overjet in a Maxil- lary Denture and Phonetic Function Using a Speech Recognition System. Prosthodont Res Pract. 2006; 5(3):171-7. [Crossref]

19. Gupta R, Luthra RP, Gautam D. Phonetics in Complete Denture A Review. Int J Healthc Sci. 2016 Apr-Sep;4(1):373-377.

20. Chaturvedi S, Gupta N, Verma A, Tandan A. Speech Comprehension (Prosthetic contemplation). IOSRJDMS. 2015; 14(7):34-36. [Internet]

Please cite this article as: Husein M. Impakt of the vertical dimension of occlusion and arrangement of teeth on speech articulation (questionnaire study). J of IMAB. 2020 Apr-Jun;26(2):3198-3202.

DOI: https://doi.org/10.5272/jimab.2020262.3198

Received: 25/06/2019; Published online: 17/06/2020

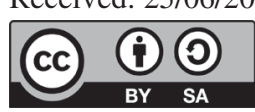

\section{Address for correspondence:}

D-r Majed Hussein,

Self-study programme PhD candidate, Department of Prosthetic Dental Medicine, Faculty of Dental Medicine, Medical University, Plovdiv,

26, Bitolja str., Plovdiv, Bulgaria

E-mail: magicdental@abv.bg, 